\title{
Period Incentive Research on the Construction Phase of PPP Project
}

\author{
Kankan Xu \\ Qingdao Technological University \\ School of Management, Qingdao Technological \\ University \\ Qingdao, China \\ jzxk1985@163.com
}

\author{
Jinxian Zhao \\ Qingdao Technological University School of \\ Management, Qingdao Technological University \\ Qingdao, China \\ zhjxqdsd@163.com
}

\begin{abstract}
The inherent characteristics of PPP financing mode demands that the participants of the project cooperation with each other and form a community of interests. In construction phase, the project company cooperates with the contractor under the mode of general contracting; meanwhile their game relationship determines whether the project is going to success. Through establishing a principal-agent game model between the project company and the contractor and then discussing their game relationship in the view of period incentive, this paper compares the form of period incentive under the condition of information symmetry with that of information asymmetry, on the basis of which we analyze the optimization problem of period incentive and then reach the optimal form of incentive measures.
\end{abstract}

Keywords-construction period incentive; contractor; PPP; principal-agent game model; project company

\section{FOREWORD}

PPP financing model, whose literal translation of the Chinese is "public-private partnership", refers to a cooperation model between public sector and private investor, which is a new model aiming at bringing private capital into public domain in order to resolve the shortage of public fund. The construction and operation of PPP project usually need the cooperation among multiple principals, including public sector, private investor, project company, contractor, raw material suppliers, operator, financial institution and ultimate user $[1,2]$.

Compared with other financing mode of concessions, PPP mode has its own feature: 1 the philosophy of project cooperation. PPP mode emphasizes that a "win-win" situation shall be reached among different stakeholders in the form of cooperation based on a franchise project, in particular the public sector transforms into a partner with other stakeholders in the project period form a supervisor. So it becomes easy for every partner to form a community of interests, and then avoids the appearance of ignoring the overall interests because of egoism; 2 the way of sharing benefits and risks. Private investor gets involved at the initial phase of the project, interests and risks are shared, all of which constitute a cooperation relationship that promotes the internal coordination among different participants. Thus it can be seen that PPP mode lays more stress on promoting a community of interests among the participants so as to maximize the interests of the whole project, in that way, an optimized collaboration must be explored among them. The main participants during the construction period of PPP project are project company and contractor, so their cooperation determines whether the project's construction will be successful $[1,3]$. Therefore this paper focuses on the cooperation between the project company and the contractor and then analyzes their game relationship.

\section{CONSTRUCTION PERIOD INCENTIVE OF PPP PROJECT}

Project Company is a limited liability company who is independent and responsible for its own profits and losses. Usually it's set up in the project-host country by project sponsor in order to manage and operate the project better. The fund from different sponsors becomes the project's equity capitallcapital fund, also known as stoke. The contractor signs an EPC general contract and when the concession period is confirmed, what the project company will do is entrusting a contractor with the construction. Among all common contract models, general contract model can decrease the number of contractors that the project company needs to face as little as possible in order to make the project an integrated system and avoid the phenomenon of multiple leaderships; therefore it benefits the overall control. In the international engineering item building, large international contractors mostly adopt general contracting model [5]. Under the model of general contracting, the project company signs a "fixed price and rewards" contract, and then uses the measure of period incentive, in other words, with the project's quality guaranteed they will offer rewards to the contractor if the project is completed before the due date according to the contract, conversely they will give corresponding punishment [6,7].

The period incentive can push the contractor to put more resources into the construction so as to shorten the work period, but increasing resources means the cost will rise. Considering that, the contractor would like to choose the best construction efficiency for them, and because the actual construction time limit is determined by not only the contractor's construction efficiency but also the external environment, especially when the actual efficiency is unobserved, it's very likely that the phenomena of moral hazard[8]. Therefore this paper will regard the project company as the client and the contractor as the agent, in which way we establish a game model to solve the optimization problem of the period incentive under the 
condition that the actual efficiency is observable or unobservable $[9,10]$.

\section{Summary OF PPP PRoJect INCENTIVE MOdEL}

Under the period incentive, if the contractor completes the project before the completion date according to the contract, the project company shall offer rewards to the contractor, but when the completion of the project comes later than the due date, they shall give corresponding punishment [6]. On the basis of description above, the period incentive model that the project company offers to the contractor can be described as:

$$
w(t)=\omega_{0}+\omega_{1}\left(t_{0}-t\right)
$$

Thereinto, $t_{0}$ means the time limit as agreed by both sides; $t$ means the actual construction time limit; $\omega_{0}$ means the total fixed revenue that the contractor will obtain if they complete the project on time; means corresponding reward or punishment that the contractor receive. But the actual construction time limit $t$ depends on not only the contractor's efficiency, but also the external environment, so it can be described as:

$$
t=t(e, \theta)=\frac{k}{e}+\delta \theta
$$

Thereinto $k$ means the total volume of project operation; $e$ means the contractor's actual construction efficiency, which is the volume of operation per unit time; $\theta$ a random variable, means external uncertainties that affect the actual operation time; $\delta$ means the extent of the impact from external factors to the actual operation time.

However, the contractor's actual construction efficiency and the external factors are usually unobservable, which result in that the period incentive model cannot take both of them into consideration. If so, the contractor will certainly make use of this inscrutability and choose the best construction efficiency for them, then turn over to blaming the project delay on the external factors, which is named the phenomena of moral hazard [8]. In order to prevent this phenomenon, the project company needs to motivate the contractor according to (1) on the basis of actual construction time limit observed. In other words, the amount of reward or punishment the contractor receive will be judged only by the actual construction efficiency, in which case the contractor would like to choose a efficiency that can confirm their interests with the project company's so as to maximize their interest at the same time.

\section{MOdEl SPECIFICATION OF PPP PROJECT PERIOD INCENTIVE}

Next we shall regard the project company as the client and the contractor as the agent, in which way we build the model [10-12].

\section{A. Model Specification}

Let's suppose that the concession period of PPP project is $T$, the income per unit time in the future is $R$. According to (2), the actual prospective earnings of the project company can be described as:

$$
\pi=\pi(e, \theta)=R[T-t(e, \theta)]
$$

If PPP project is done on time, the project company will receive the prospective income $r_{0}$, and $r_{0}=R\left(T-t_{0}\right)$; besides when the project's fulfillment comes ahead of the due date, the prospective income of the project company will be more than $r_{0}$, conversely, the income will be less than $r_{0}$.

Let's suppose that the construction cost is $C_{0}$, the scale and quality of the project is affected by the investment, in other words the quality of the project will be better when the construction cost rises, in which case the maintenance cost will decrease with a better quality after the project is done, so the maintenance cost per unit time can be described as: $H=H(C)=h C^{-\alpha}$, among which $h>0$ means maintenance cost coefficient, $\alpha>0$ is constant, and by the means of regression method the numerical value of $h$ and $\alpha$ can be acquired from similar projects' historical statistical data. During the concession period of PPP project, $Z$ the total investment from the project company can be described as:

$$
Z(e, \theta)=C+H(T-t(e, \theta))=C+h C^{-\alpha}(T-t(e, \theta))
$$

Consequently, if the contractor accepts what (1) show, the project company's prospective income can be figured out through the following equation:

$$
E_{\theta}[v(\pi(e, \theta)-w(t(e, \theta))-Z(e, \theta))]
$$

Thereinto, $E_{\theta}$ is expectation operator, $v$ is utility function.

When (5) is considered as objective function, what the project company is confronted with is inspiring the contractor according to (1) with the measures $w(t)$ so as to gain a maximized expected utility. That is an optimization problem that should meet two restraints named participation constraint and incentive compatible constraint [13-15].

Participation constraint means the expected utility of the contractor in the situation that they accept the project company's incentive measures should be more than that when they do not accept. The maximized expected utility the contractor can obtain when they refuse the incentive measures is decided by the market opportunity, and it can be called reservation utility $[13,16]$. Let's suppose that the reservation utility is $\bar{\mu}$, and construction cost is a function (recorded as $c(e)$ ) of construction efficiency, then participation constraint can be described as: 


$$
E_{\theta}[u(w(t(e, \theta))-c(e))] \geq \bar{\mu}
$$

Thereinto $u(\cdots)$ is utility function of the contractor, so the left of (6) is the expected utility of them.

Incentive compatible constraint means that the contractor will certainly choose a construction efficiency which can maximize their expected utility whatever incentive measures the project company offers. Then it will result in that the construction efficiency expected by the project company can be achieved only by the maximization of the contractor's expected utility. So incentive compatible constraint can be described as:

$$
E_{\theta}[w(t(e, \theta))-c(e)] \geq E_{\theta}[w(t(e, \theta))-c(e)], \forall e \geq 0
$$

According to the description above, the optimization problem of PPP project period incentive measures that the project company confronts can be presented with the principal-agency model by the equation as follows:

$$
\begin{gathered}
\max _{w(t)} V=E_{\theta}[v(\pi(e, \theta)-w(t(e, \theta))-Z(e, \theta))] \\
\text { s.t. } E_{\theta}[u(w(t(e, \theta))-c(e))] \geq \bar{\mu} \\
\max _{e \geq 0} U=E_{\theta}[u(w(t(e, \theta))-c(e))]
\end{gathered}
$$

\section{B. Postulated Conditions of the Model}

Combining actual conditions, presenting postulated condition of the model should allow for some points below:

1) The Project Company must cover their cost during the concession period, so the prospective net earnings should be greater than zero;

2) Construction process is affected by external uncertainty factors, which is divided into two sides: favorable factor and negative factor.

3) Under certain conditions, improving the construction efficiency needs to increase more resources, while it brings a higher cost. In addition higher efficiency means more resources.

4) Uncertainty factors may result in delay of the project, which is a risk that the contractor wants to avoid, so their utility function has the characteristics of risk avoidance. But the project company must face up to this risk, so their expected utility equals to the expected earnings [14].

Considering the situation above, we can make assumptions as follows:

Assumption 1: The net earnings per unit time of PPP project in the future are greater than zero, that is:

$$
R-H=R-h C^{-\alpha}>0
$$

Assumption 2: The random variable $\theta$ follows Gaussian distributions in $[-\infty,+\infty]$, and expectation of it is 0 , the variance is $\sigma^{2}$.

Assumption 3: The construction level and marginal construction cost of the general contractor in PPP project increases with the rise of construction efficiency, that is:

$$
d c(e) / d e>0, d^{2} c(e) / d e^{2}>0
$$

Than we can define that:

$$
c(e)=\beta e^{2} / 2
$$

Thereinto reflect the contractor's technological level, and when its numerical value is greater, the technological level will be lower; conversely, the technological level will be higher.

Assumption 4: The project company is risk neutral while the contractor tends to avoid risk. The utility function of the contractor has a constant and absolute characteristic of risk avoidance. That is:

$$
u(X)=-\exp (-\rho X)
$$

Among (14) $\rho>0$ means the degree of absolute risk avoidance, when $\rho=0$ it means the contractor is risk neutral, and $X$ shows the contractor's actual earnings [14].

V.

THE OPTIMAL Form OF PERIOd INCENTIVE IN PPP PROJECT

Result of the game between the project company and the contractor determines whether the construction phase is going to success will be solved in two cases, that is both sides are under the condition of information symmetry(the construction efficiency is observable) and information asymmetry(the construction efficiency is unobservable)[17].

A. The Period Incentive When the Efficiency is Observable

When the actual construction efficiency of the general contractor is observable, that is the condition of information symmetry, any efficiency that meets the participation constraint and maximizes the interests of the project company can be realized through a contract between the both, so the project company needn't to consider the incentive compatible constraint. In that way, with plugging (1) to (4) into (8) and (13), (14) into (9), the project company can find out the optimal solution, as is shown below:

$$
\begin{gathered}
\max _{e, \omega_{0}, \omega_{1}} V[R-H(C)]\left(T-\frac{k}{e}\right)-\omega_{0}-\omega_{1}\left(t_{0}-\frac{k}{e}\right)-C \\
\text { s.t. } \bar{U}=\omega_{0}+\omega_{1} t_{0}-\frac{k}{e} \omega_{1}-\frac{1}{2} \beta e^{2}-\frac{1}{2} \rho \omega_{1}^{2} \delta^{2} \sigma^{2} \geq \bar{\omega}
\end{gathered}
$$


In (16), $\bar{\omega}$ means opportunity benefit of the contractor, and $u(\bar{\omega})=\bar{\mu}$, that is to say reservation utility equals to the utility level that corresponds the opportunity benefit. Therefore (16) shows that the contractor's certainty benefit will not be less than the opportunity benefit, in addition, (16) is equivalent to (9) for the following reasons:

According to the assumption 4, the expected utility of the contractor $U$ is gained from the certainty benefit $\bar{U}$. That is:

$$
\begin{gathered}
U=E_{\theta}[u(w(t(e, \theta))-c(e))] \\
=\int_{-\infty}^{+\infty}-\exp (-\rho(w-c(e))) \frac{1}{\sqrt{2 \pi} \sigma_{w}} \exp \left(-\frac{\left(w-u_{w}\right)^{2}}{2 \sigma_{w}^{2}}\right) d w \\
=-\int_{-\infty}^{+\infty} \exp \left(-\rho\left(\sigma_{w} y+\mu_{w}-c(e)\right)\right) \frac{1}{\sqrt{2 \pi}} \exp \left(-\frac{y^{2}}{2}\right) d y \\
=u\left(E[w(t(e, \theta))]-c(e)-\frac{1}{2} \rho \operatorname{Var}(w(t(e, \theta)))\right) \\
=u\left(\omega_{0}+\omega_{1} t_{0}-\frac{k}{e} \omega_{1}-\frac{1}{2} \beta e^{2}-\frac{1}{2} \rho \omega_{1}^{2} \delta^{2} \sigma^{2}\right)=u(\bar{U})
\end{gathered}
$$

Moreover, the utility function of the contractor is incremental according to (14). That is:

$$
\frac{\partial u}{\partial X}=\rho \exp (-\rho X)>0,(\rho>0)
$$

For the optimization problem above, we can consider the equation bellow:

$$
\begin{gathered}
\nabla V\left(e^{*}, \omega_{0}^{*}, \omega_{1}^{*}\right)+\lambda \nabla \bar{U}\left(e^{*}, \omega_{0}^{*}, \omega_{1}^{*}\right)=0 \\
\lambda(\bar{U}-\bar{\omega})=0
\end{gathered}
$$

Thereinto $\lambda \geq 0$ is named Kuhn-Tuker multiplier[18-20]. From (19) and (20) we can find out that the optimal solution of the problem above is:

$$
e^{*}=\left[\frac{k\left(R-h C^{-\alpha}\right)}{\beta}\right]^{\frac{1}{3}}
$$

$$
\begin{gathered}
\omega_{1}^{*}=0 \\
\omega_{0}^{*}=\bar{\omega}+c\left(e^{*}\right)
\end{gathered}
$$

In conclusion, when the efficiency of the general contractor is observable, the optimal expected profit of the project company is:

$$
V\left(e^{*}, \omega_{0}^{*}, \omega_{1}^{*}\right)=\left[R-h C^{-\alpha}\left[T-\frac{k}{e^{*}}\right]-\omega_{0}^{*}-C\right.
$$

From (21) to (24), we can get the following conclusion:

1) There is a positive correlation between the optimal efficiency $e^{*}$ and the investment volume $C$, the total volume of project operation $k$, the income per unit time in the future, while a negative correlation between $e^{*}$ and the coefficient of construction cost.

2) The optimal expected profit of the project company rises with the improving of the contractor's construction level, while it's irrelevant to incentive intensity. The expected profit exactly equals the expected net income minus the fixed amount given to the contractor and the construction cost. That is to say the project company needn't to motivate the contractor with any incentive measure, and define the construction period like the following model:

$$
w(e)=\left\{\begin{array}{l}
\bar{\omega}+c\left(e^{*}\right), e=e^{*} \\
\omega<\bar{\omega}, e \neq e^{*}
\end{array}\right.
$$

In a word, the project company can demand that the contractor do their work at $e^{*}$ sufficiently so as to maximize the expected profit. Under this condition the contractor will get a fixed income, which is the sum of the opportunity benefit and the construction cost. If not the contractor's income will be less than. So the model above can combine the project company's benefits target with the contractor's.

\section{B. The Period Incentive When the Efficiency is Unobservable}

When the actual construction efficiency of the general contractor is unobservable, that is the condition of information asymmetry, from (17) and (18) firstly we can draw out that (10) is equivalent to:

$$
\max _{e \geq 0} \bar{U}=\omega_{0}+\omega_{1} t_{0}-\frac{k}{e} \omega_{1}-\frac{1}{2} \beta e^{2}-\frac{1}{2} \rho \omega_{1}^{2} \delta^{2} \sigma^{2}(26)
$$

On the basis of the equation above, the contractor's optimal strategy can be described as: 


$$
e=e\left(\omega_{1}\right)=\left(\frac{\omega_{1} k}{\beta}\right)^{\frac{1}{3}}
$$

When the contractor chooses the construction efficiency in accordance with (27), the problem that the project company faces will be solving the following equation:

$$
\begin{aligned}
& \max _{\omega_{0}, \omega_{1}>0} V=\left(R-h C^{-\alpha}\right)\left(T-\frac{k}{e\left(\omega_{1}\right)}\right)-C-\omega_{0}-\omega_{1}\left(t_{0}-\frac{k}{e\left(\omega_{1}\right)}\right) \\
& \text { s.t. } \omega_{0}+\omega_{1} t_{0}-\frac{k}{e\left(\omega_{1}\right)} \omega_{1}-\frac{1}{2} \beta\left[e\left(\omega_{1}\right)\right]^{2}-\frac{1}{2} \rho \omega_{1}^{2} \delta^{2} \sigma^{2} \geq \bar{\omega}
\end{aligned}
$$

Taking the theory of Kuhn-Tuker [18-20], (29) will certainly take the equal sign, and then (28) can be translated into:

$$
\begin{aligned}
& \max _{\omega_{0}, \omega_{1}>0} V=\left(R-h C^{-\alpha}\right)\left(T-\frac{k}{e\left(\omega_{1}\right)}\right)-C-\frac{1}{2} \beta\left[e\left(\omega_{1}\right)\right]^{2} \\
& -\frac{1}{2} \rho \omega_{1}^{2} \delta^{2} \sigma^{2}-\bar{\omega}
\end{aligned}
$$

Judging from (30), we can put forwards the following propositions:

1) (30) must have a unique solution in $(0,+\infty)$, and when $\omega_{1}=\omega_{1}^{* *}$, the following equation is right:

$$
g\left(\omega_{1}\right)=3 \rho \delta^{2} \sigma^{2} \omega_{1}^{\frac{7}{3}}+\beta^{\frac{1}{3}} k^{\frac{2}{3}} \omega_{1}-\beta^{\frac{1}{3}} k^{\frac{2}{3}}(R-H)=0
$$

2) The optimal solution $\omega_{1}^{* *}$ meets the following properties: $\omega_{1}^{* *} \leq R-h C^{-\alpha}$, only if $\rho \delta \sigma=0$, the equation will take the equal sign; when $\rho \delta \sigma \neq 0, \omega_{1}^{* *} \in(0, R-H)$, and it's related to $R-H(C), \beta k^{2}, \rho \delta^{2} \sigma^{2}$.

Then the optimal form of incentive model under the condition that the contractor's actual efficiency is unobservable is:

In conclusion, under the condition of information asymmetry, we can draw out some following results from the game relationship between the project company and the contractor.

a) The contractor will choose their actual efficiency depending on the incentive intensity from the project company, and when the intensity is higher, the actual efficiency will be higher.

b) If the optimal incentive is launched, rewards to the contractor will not be more than the net income per unit time in the future, and it's affected by some other factors, such as prospects of the project operation, scale, uncertainty risks, technical merit of the contractor and degree of risk aversion.

c) Under the condition of information asymmetry, the optimal form of incentive has nothing to do with the time limit agreed. The project company will offer rewards just according to actual time limit, and when the time limit is shorter, the rewards will be greater.

\section{Comparison and Analysis of the Two Situations}

The comparison and analysis of the two situations will be judged by two numerical values, that is the project company's optimal expected benefits and the optimal time limit. Firstly, it's the comparison of the optimal expected benefits. We plug $\omega_{0}^{* *}, \omega_{1}^{* *}$ into (28) and get the optimal expected interests under the condition of information asymmetry:

$$
\begin{aligned}
& V\left(\omega_{0}^{* *}, \omega_{1}^{* *}\right)= \\
& {[R-H]\left[T-\frac{k}{e\left(\omega_{1}^{* *}\right)}\right]-C-\left[\bar{\omega}+\frac{1}{2} \beta\left[e\left(\omega_{1}^{* *}\right)\right]^{2}+\frac{1}{2} \rho \delta^{2} \sigma^{2}\left(\omega_{1}^{* *}\right)^{2}\right]}
\end{aligned}
$$

$$
\begin{aligned}
& V\left(e^{*}, \omega_{0}^{*}, \omega_{1}^{*}\right)-V\left(\omega_{0}^{* *}, \omega_{1}^{* *}\right)= \\
& \frac{\left(\beta k^{2}\right)^{\frac{1}{3}}\left[7(R-H)+2 \omega_{1}^{* *}-9(R-H)^{\frac{2}{3}}\left(\omega_{1}^{* *}\right)^{\frac{1}{3}}\right]}{6\left(\omega_{1}^{* *}\right)^{\frac{1}{3}}}=f\left(\omega_{1}^{* *}\right)
\end{aligned}
$$

For $f\left(\omega_{1}^{* *}\right)$, we can reach that:

$$
\begin{aligned}
& \frac{\partial f\left(\omega_{1}^{* *}\right)}{\partial \omega_{1}^{* *}}=\frac{\left(\beta k^{2}\right)^{\frac{1}{3}}}{6}\left[\frac{4}{3}\left(\omega_{1}^{* *}\right)^{-\frac{1}{3}}-\frac{7}{3}(R-H)\left(\omega_{1}^{* *}\right)^{-\frac{1}{3}}\right] \leq \\
& \frac{\left(\beta k^{2}\right)^{\frac{1}{3}}}{6}\left[\frac{4}{3}\left(\omega_{1}^{* *}\right)^{-\frac{1}{3}}-\frac{7}{3} \omega_{1}^{* *}\left(\omega_{1}^{* *}\right)^{-\frac{4}{3}}\right]<0
\end{aligned}
$$

According to the equation above, we can find out that:

$$
V\left(e^{*}, \omega_{0}^{*}, \omega_{1}^{*}\right)-V\left(\omega_{0}^{* *}, \omega_{1}^{* *}\right)=f\left(\omega_{1}^{* *}\right) \geq f(R-H)=0
$$

As is shown in (35), the optimal expected interests under the condition of information asymmetry will not be more than that under the condition of information symmetry.

Next we come to the comparison of the optimal time limit. That is the comparison between $E_{\theta}\left[t\left(e^{* *}, \theta\right)\right]$ and $E_{\theta}\left[t\left(e^{*}, \theta\right)\right]$.

$$
E_{\theta}\left[t\left(e^{* *}, \theta\right)\right]\left(\frac{\beta k^{2}}{\omega_{1}^{* *}}\right)^{\frac{1}{3}} \geq\left(\frac{\beta k^{2}}{R-H}\right)^{\frac{1}{3}}=E_{\theta}\left[t\left(e^{*}, \theta\right)\right]
$$

We can see that the optimal time limit under the condition of information asymmetry will not be more than that under the condition of information symmetry. Consequently, considering the target of completing the project as soon as possible and receiving benefits of 
operation, the project company will certainly need to strengthen the incentive intensity in order to push the contractor to increase resources and improve the efficiency. So the prospects of expected earnings must be preferable, in which case more rewards can be offered by the project company.

\section{CONCLUSIONS}

This paper carries out the analysis of the game relationship between the project company and the contractor in the construction phase of PPP project base on the principal-agent model, and solves the problem about the optimal form of the incentive measures. After that, we know that both of the optimal expected interests and time limit under the condition of information asymmetry won't be more than that under the condition of information symmetry. In addition, because of the external environment, the project always lies in the situation of information asymmetry. Therefore, the project company must consider not only the contractor's construction merit but also the prospects of the expected earnings in the operation phase. Only if the prospect of operation is preferable, it will be easy to bring the two sides into a whole for the interests to complete the project successfully and benefit the both.

\section{REFERENCES}

[1] Chen Fei. Studies on the interests' coordination and distribution of stakeholders in PPP project [D]. Chongqing University, Chongqing. 2008.J. Clerk Maxwell, A Treatise on Electricity and Magnetism, 3rd ed., vol. 2. Oxford: Clarendon, 1892, pp.68-73.

[2] Hang Huai-nian, Wang Jian-ping. The establishment of game form and cooperative mechanism between the public and private [J]. Construction Economics, 2008(9): 40-42.

[3] Wang Rui. Studies on management and cooperation of stakeholders in construction project [D]. Central South University, Changsha. 2008.

[4] Wang Shou-qing, Ke Yong-jian. Financing of franchise project (BOT, PFI and PPP) [M]. Beijing, Tsinghua University Press, 2008.53-55.
[5] Cheng Hu. Management of construction object [M]. Beijing, Higher Education Press, 2009. 103-104.

[6] Zhang Gui-sheng. Contractual approach for shortening the time limit of highway project [J]. Journal of China \& Foreign Highway, 1998, 18(6): 42-44.

[7] Berends T C. Cost plus incentive fee contracting-experienced structuring [J]. International Journal of Project Management, 2000, 18(3): $165-173$.

[8] Kim S K, Wang S S. Linear contracts and the double moral hazard [J]. Journal of Economic Theory, 1998, 82(3): 342-378.

[9] Song Yi-luan. Game Analysis of Public Infrastructure Investment of Local Governments [D]. East China Normal University, Shanghai. 2009

[10] Wu Xiao-ling. Study on Interests Coordination Mechanism for BOT Project Participants Based on Game Model [D]. Nanjing University, Nanjing. 2011.

[11] Cheng Pan-jun. Project construction process quality control based on game theory [D]. Hebei University of Technology, Tianjin. 2007.

[12] Ni Zhi-hua. Research of engineering change based on principal-agent model [D]. Southwest Jiaotong University, Chengdu. 2011.

[13] Fudenberg D, Jean T. Game Theory [M]. MIT Press, 1991, Chapters 6-7.

[14] Zhang Wei-ying. Game theory and economics of information [M]. Shanghai, People's Publishing House, 2003.

[15] Xiao Tiao-jun. Game theory and its application [J]. Shanghai, Sanlian Bookstore. 2004.

[16] Liu Yu-xun, Shan Yu. The broadening of principal-agent model [J]. Journal of Zhaoqing University, 2011, 32(6): 28-32.

[17] Zheng Wang-yun. Research of incentive mechanism in engineering project based on principal-agent theory [D]. Tianjin University, Tianjin. 2008.

[18] Aubin JP. Mathematical Methods of Game and Economic Theory [M]. North-Holland, Amsterdam, 1979.

[19] Aubin JP. Optimization and Equilibration: an Introduction to Nonlinear Analysis[M]. Spring-Verlag, New York, 1998.

[20] Chiang AC. Fundamental Methods of Mathematical Economics (3rd edition)[M]. McGraw-Hill, 1984. 